\title{
Avaliação de fornecedores de chapa de aço em uma empresa de implementos rodoviários baseada na abordagem multicritério: um estudo de caso
}

\author{
Emanuely Paskally Medeiros Sousa ${ }^{\mathrm{a} *}$, Breno Barros Telles do Carmo ${ }^{\mathrm{b} * *}$ \\ a*Universidade Federal Rural do Semi-Árido, Mossoró, RN, Brasil, paskallymedeiros@yahoo.com.br \\ b**Universidade Federal Rural do Semi-Árido, Mossoró, RN, Brasil, brenobarros@ufersa.edu.br
}

\begin{abstract}
Resumo
Ao avaliar ou selecionar fornecedores, os gestores das empresas, em alguns casos, baseiam-se no conhecimento tácito obtido por meio de sua experiência para tomar a decisão, o que pode resultar em avaliações imprecisas, dada a existência de inúmeras alternativas que, por vezes, podem ser conflitantes entre si. Diante desse fato, o presente estudo focou uma indústria de implementos rodoviários localizada no oeste do estado do Rio Grande do Norte que enfrenta problemas com os fornecedores de chapa de aço, principal matéria-prima necessária à produção dos implementos rodoviários. Este trabalho tem como objetivo aplicar um modelo da abordagem MCDA para avaliar os fornecedores de chapa de aço. Constatou-se que a utilização do modelo serviu como ferramenta para a transformação do conhecimento tácito em conhecimento explícito, pois as informações detidas pelo decisor passaram para a empresa, estando disponíveis a qualquer momento, independente de quem comandar o departamento de compras.
\end{abstract}

Palavras-chave

Implementos rodoviários. Seleção de fornecedores. Modelagem Multicritério de Apoio à Decisão.

\section{Introdução}

Independentemente do setor no qual as empresas estão inseridas, as atividades relacionadas ao processo de seleção e avaliação de fornecedores são extremamente importantes, pois a concorrência entre as cadeias de suprimentos vem assumindo escala global e uma postura cada vez mais agressiva, o que exige um maior empenho das organizações no desenvolvimento de novas ferramentas de gestão direcionadas ao aprimoramento e melhoria contínua do desempenho com relação às constantes mudanças e exigências do mercado (Alencar et al., 2007).

0 problema da seleção de fornecedores (Supplier Selection Problem - SSP) baseia-se na análise e medição da performance de fornecedores, com o objetivo de selecioná-los e classificá-los de acordo com o preenchimento dos requisitos exigidos pelo mercado (Sonmez, 2006).

O SSP, segundo o mesmo autor, pode ser considerado um problema de decisão multicritério por avaliar inúmeras alternativas e critérios qualitativos (aqueles baseados na preferência e julgamento dos decisores) e quantitativos (valores monetários), que podem ser conflitantes entre si, o que torna complexa a tarefa de relacioná-los em um único modelo de avaliação e/ou seleção de fornecedores.

É nesse contexto que a abordagem multicritério contribui para o processo de apoio à decisão, fornecendo elementos para subsidiar o processo decisório (Hammond et al., 1999).

No processo de tomada de decisão, na maioria dos casos, o gestor baseia-se apenas em sua experiência, sem fazer uso de modelos matemáticos ou métodos que ofereçam suporte para isso. Esse conhecimento empírico pode gerar erros na avaliação. É por esse motivo que a modelagem multicritério é indicada, fornecendo à empresa informações que auxiliam o gestor a decidir qual fornecedor atende aos critérios mais relevantes para a empresa (Luo et al., 2009). 
Diante do exposto, este estudo foi realizado em uma indústria de implementos rodoviários localizada no oeste do estado do Rio Grande do Norte, com filiais nas cidades de Natal e Fortaleza. 0 desafio apresentado neste estudo foi a avaliação de fornecedores de chapa de aço, principal matéria-prima necessária à produção dos implementos rodoviários, a partir da visão do gerente de compras da empresa, considerado o decisor nessa análise. Os fornecedores e supervisores contribuíram para o conhecimento do problema e aplicação do método de avaliação. Os aspectos identificados como relevantes no processo decisório, segundo a visão desses atores, foram priorizados, quantificados e ponderados. Nesse sentido, este trabalho teve como objetivo avaliar os fornecedores de chapa de aço por meio da abordagem multicritério de apoio à decisão.

Foi realizada uma pesquisa de campo para a coleta dos dados por meio de dois roteiros de entrevista (disponíveis nos Anexos A e B). Dez entrevistas foram pré-agendadas durante o desenvolvimento desta pesquisa, fato que evidencia a existência da interação entre o pesquisador e o objeto de pesquisa. Em função das características listadas acima, esta pesquisa se enquadra como um estudo de caso (Miguel et al., 2012).

Como resultado pôde ser observado que a abordagem Multiple Criteria Decision Aid (MCDA) proporcionou a transformação do conhecimento tácito em conhecimento explícito para a organização no que tange ao processo de seleção de fornecedores, gerando informações que ficaram disponíveis, independentemente do gestor responsável pelo departamento de compras. Como o setor de Planejamento e Controle de Produção (PCP) da empresa ainda apresenta falhas de planejamento, o fornecedor melhor avaliado ainda não pode ser priorizado devido ao fato de ele definir, para os pedidos recebidos, alguns requisitos não compatíveis com a atual estrutura do PCP da empresa.

\section{Fundamentação teórica}

\subsection{O problema de seleção de fornecedores}

A globalização e a internet ampliaram as opções de fornecedores para as organizações, o que torna o processo de tomada de decisão mais complexo. Nesse sentido, selecionar um grupo competente de fornecedores é uma tarefa desafiadora para as empresas (De Boer et al., 2001; Weber et al., 1991).

De Boer et al. (2001) identificaram a existência de alguns métodos para fazer a seleção de fornecedores. Esses métodos são classificados em métodos de prequalificação dos fornecedores e métodos de decisão final por escolha. Os métodos de prequalificação de fornecedores (De Boer et al., 2001) são subdivididos em:

- Métodos categóricos qualitativos: Análise baseada em dados históricos e na experiência prévia da empresa com o fornecedor. 0 fornecedor é avaliado como positivo, neutro ou negativo.

- Data Envelopment Analysis (DEA): Análise baseada na avaliação da eficiência dos fornecedores.

- Análise de cluster: Método estatístico que usa um algoritmo de classificação para agrupar os fornecedores em função da proximidade dos resultados obtidos pelos indicadores.

Em relação aos métodos de decisão final por escolha, os autores os subdividem em:

- Métodos de ponderação linear: Nesses casos, pesos são atribuídos a cada critério avaliado para a geração de uma avaliação global do fornecedor.

- Métodos de custo por propriedade: São métodos que buscam quantificar os custos na escolha do fornecedor dentro do ciclo de vida do item comprado.

A seleção de fornecedores tem como objetivo reduzir o risco existente na atividade de compra, minimizar os gastos e construir relacionamentos confiáveis e de longo prazo entre compradores e fornecedores (Guarnieri dos Santos, 2012; Cheraghi et al., 2004).

Assim, o problema de seleção de fornecedores é considerado de natureza multicriterial, dado o objetivo de encontrar um fornecedor que atenda a inúmeros critérios. É comum, entretanto, que a solução para esse tipo de problema seja dada de forma monocriterial, ou seja, quando um único critério é priorizado em detrimento dos demais (Alencar \& Almeida, 2008).

Observa-se, contudo, que existem obstáculos a esse processo, relacionados à quantificação dos critérios qualitativos e também à existência de critérios conflitantes, como a minimização dos custos e a maximização da qualidade, o que pode ser resolvido por meio de compensação de valor entre atributos (Franco \& Montibeller, 2010; Luo et al., 2009), o que torna explícita a diferença de importância dos critérios para o cliente, facilitando a priorização do que é realmente importante para ele.

\subsection{Critérios utilizados para a seleção de fornecedores}

Ha \& Krishnan (2008) afirmam que, ao longo dos anos, diversos modelos multicritério foram propostos, bem como vários critérios foram utilizados na avaliação e seleção de fornecedores, variando de acordo com a situação à qual eram submetidos, podendo-se concluir 
que não existe uma melhor forma de realizar esse processo, o que leva as empresas a utilizarem diversos tipos de abordagem. Cheraghi et al. (2004) realizaram uma pesquisa baseada nos fatores que influenciam o processo de seleção de fornecedores identificados por Dickson (1966), considerado uma referência na área de seleção de fornecedores. Nesse trabalho, os autores identificaram os seguintes elementos como os mais importantes no processo de avaliação de fornecedores: qualidade, entrega, serviços pós-venda, capacidade técnica, situação financeira, gestão e organização e localização geográfica.

No presente trabalho será dada atenção especial à pesquisa de Dickson (1966), que identificou 23 critérios levados em consideração no momento da seleção de fornecedores. A pesquisa de Stavropolous (2000) englobou artigos publicados entre 1966 e 2000, com a identificação dos 30 critérios mais utilizados no processo de avaliação e seleção de fornecedores. Por fim, Guarnieri dos Santos (2012) defende em sua tese, baseando-se em 45 artigos publicados entre 2001 e 2011, a existência de 99 critérios, sendo 18 deles mais frequentes entre os artigos pesquisados.

A Tabela 1 apresenta os critérios usados tanto na seleção como na avaliação de fornecedores, sendo possível observar quais critérios permaneceram com o passar dos anos, quais foram desconsiderados e quais critérios são novos.

A Tabela 1 apresenta os critérios usados na seleção e avaliação dos fornecedores com base em três autores supracitados. Verifica-se que, apesar do passar dos anos e das mudanças na forma de as organizações gerirem seus negócios, muitos quesitos utilizados pelas empresas no momento de avaliar fornecedores

Tabela 1. Comparativo entre critérios utilizados no processo de seleção de fornecedores.

\begin{tabular}{|c|c|c|}
\hline Dickson (1966) & Stavropolous (2000) & Guarnieri dos Santos (2012) \\
\hline Preço líquido & Preço & Preço/Custo \\
\hline Qualidade & Qualidade & Qualidade \\
\hline \multirow{2}{*}{ Cumprimento de cronogramas de entrega } & \multirow{2}{*}{ Entrega } & Entrega (on-time) \\
\hline & & Entregas atrasadas \\
\hline Serviço de reparo & Serviço pós-venda & Serviço \\
\hline Localização geográfica & Localização geográfica & Localização geográfica \\
\hline Situação financeira e crédito & Posição financeira & Estabilidade financeira \\
\hline As instalações e a capacidade produtiva & Facilidades e capacidade de produção & Capacidade tecnológica \\
\hline Capacidade técnica & Suporte técnico & Capacidades técnicas e organizacionais \\
\hline Organização e capacidade de gestão & Gerenciamento e organização & Gerenciamento/Organização \\
\hline Comunicação entre ambas as partes & Sistemas de comunicação & Facilidade de comunicação \\
\hline Controle de qualidade e estoque & Controles operacionais & Suporte \\
\hline Posição do fornecedor no mercado & Reputação e posição na indústria & Posição \\
\hline Atitude do fornecedor com o contratante & Atitude & Confiança mútua \\
\hline Garantias e alinhamento de políticas & Garantia e reivindicações & Culturas compatíveis \\
\hline $\begin{array}{l}\text { Capacidade de o fornecedor atender } \\
\text { requisitos de embalagem }\end{array}$ & Habilidade de embalagem & $P \& D$ \\
\hline Impressão por meio de contatos pessoais & Impressão & Respostas às exigências dos clientes \\
\hline $\begin{array}{l}\text { Disponibilidade de treinamento e } \\
\text { desenvolvimento }\end{array}$ & Apoio a treinamento & Flexibilidade \\
\hline Histórico do desempenho & Histórico de desempenho & \\
\hline Quantidade de negócios realizados & Montante de negócios passados & \\
\hline $\begin{array}{l}\text { Registro das relações de trabalho do } \\
\text { fornecedor }\end{array}$ & Manutenção & \\
\hline $\begin{array}{l}\text { Compras futuras feitas pelo fornecedor ao } \\
\text { comprador }\end{array}$ & Arranjos recíprocos & \\
\hline $\begin{array}{l}\text { Desejo do fornecedor sobre o negócio do } \\
\text { contratante }\end{array}$ & Produtos ambientalmente amigáveis & \\
\hline $\begin{array}{l}\text { Conformidade ou } \% \text { de cumprimento dos } \\
\text { procedimentos }\end{array}$ & Aparência do produto & \\
\hline & Tecnologia & \\
\hline & Facilidade de uso & \\
\hline & Capacidade técnica & \\
\hline & \begin{tabular}{|l|} 
Capacidade just-in-time \\
\end{tabular} & \\
\hline & Capacidade de e-commerce & \\
\hline & Relações de trabalho & \\
\hline & Respostas às solicitações dos clientes & \\
\hline
\end{tabular}


continuam os mesmos, como preço, qualidade, entrega no prazo, localização geográfica, situação financeira, suporte técnico, entre outros. Esse fato é ratificado na pesquisa de Cheraghi et al. (2004).

\subsection{Abordagem Multicritério de Apoio à Decisão}

A Abordagem Multicritério de Apoio à Decisão (MCDA) apresenta um conjunto de métodos utilizados para apoiar as organizações a tomarem decisões acertadas mesmo sob a influência de inúmeros critérios (Carmo et al., 2011; Ensslin et al., 2010).

A principal diferença entre a abordagem multicritério e as abordagens tradicionais da pesquisa operacional hard é a introdução do juízo de valor dos decisores nos modelos de avaliação, o que torna a abordagem multicritério subjetiva, pois um mesmo critério pode ser analisado de formas diversas dependendo do juízo de valor do decisor que está avaliando. Essa subjetividade representa uma das principais vantagens da abordagem multicritério em relação à pesquisa operacional hard (Costa et al., 2003).

De acordo com Keeney \& Raiffa (1976), a modelagem multicritério de apoio à decisão não é uma abordagem relacionada à tomada de decisão, mas serve para auxiliar nesse processo, de forma que a decisão satisfatória seja tomada de acordo com os critérios dos decisores.

Rauscher et al. (2007) sustentam que a gestão do conhecimento deve prover métodos para gerenciar tanto o conhecimento tácito como o explícito, de forma que esses possam ser usados para resolver problemas, explorar oportunidades ou tomar decisões que melhorem a performance. Segundo Nonaka \& Takeuchi (1995), o conhecimento explícito refere-se ao conhecimento transmissível em linguagem formal e sistemática.

Esse fato é constatado por Balestrin \& Verschoore (2008) quando trabalham o conceito de evolução do conhecimento dentro das organizações. A Figura 1 ilustra esse fato.

Em função dos processos de interação entre os indivíduos, os conceitos evoluem e geram soluções e

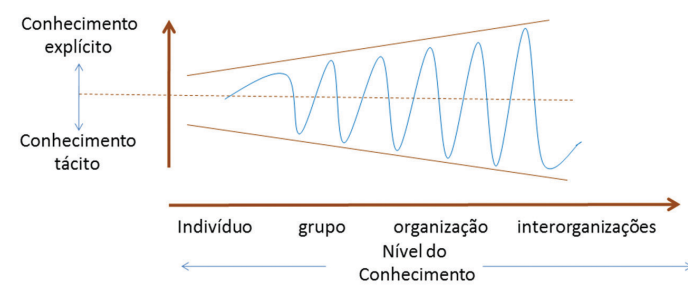

Figura 1. Evolução do conhecimento. Fonte: Balestrin \& Verschoore (2008). inovações para as organizações (Balestrin \& Verschoore, 2008). Esse fato pode ser transposto para as práticas empresariais, uma vez que a abordagem multicritério de apoio à decisão constitui um instrumento de gestão do conhecimento, permitindo a conversão do conhecimento tácito detido pelos colaboradores da empresa em conhecimento explícito, por meio da construção de mapas cognitivos, matrizes de julgamentos semânticos, descritores e seus níveis de impacto. A transformação decorrida da utilização dessa abordagem permite que o processo decisório seja questionado e reavaliado, o que implica na aprendizagem organizacional.

Existem inúmeros métodos de abordagem multicriterial que auxiliam no processo de tomada de decisão. 0 MACBETH foi o método empregado na realização deste trabalho por possibilitar a construção de um modelo de caráter quantitativo sem que seja necessário recorrer a representações numéricas diretas para definir as preferências do decisor. Ele tem como foco principal a abordagem de problemas de seleção e de ordenação. Esse método possui características tanto da escola norte-americana como da escola europeia com relação aos métodos de apoio à decisão multicritério, embora, seja notório que esse contemple mais características da primeira escola do que da segunda (Costa et al., 2003; Oliveira \& Lourenço, 2002).

\section{Metodologia}

0 enquadramento metodológico da pesquisa ocorreu da seguinte maneira: a natureza do objetivo se classifica como empírica descritiva, dado que ela utilizou a abordagem multicritério de apoio à decisão para descrever e modelar um processo de seleção de fornecedores a partir da interação entre os decisores e facilitadores (Miguel et al., 2012).

Os procedimentos para a coleta de dados dessa pesquisa são de origem primária, uma vez que são obtidos por meio de entrevistas com os decisores do processo (Marconi \& Lakatos, 2003; Gil, 2002). Por se tratar da avaliação de fornecedores de uma empresa, a pesquisa se enquadra como um estudo de caso, já que será realizada uma análise aprofundada de um objeto, utilizando inúmeros instrumentos de coleta de dados, além da existência da interação entre pesquisador e objeto de pesquisa (Miguel et al., 2012; Yin, 2001).

A abordagem MCDA é considerada um instrumento adequado para esse tipo de trabalho por adotar valores individuais dos decisores no desenvolvimento do processo de avaliação. Nesse sentido, existem alguns passos que foram seguidos para a aplicação da 
abordagem MCDA (Hammond et al., 1999; Chen et al., 2013; Carmo et al., 2011):

- Definir os objetivos de decisão;

- Determinar os atributos (medidas de performance) em consonância com o objetivo proposto;

- Hierarquizar os atributos;

- Determinar os pesos de cada atributo;

- Definir as alternativas candidatas;

- Avaliar as alternativas segundo os pesos adotados; e

- Estabelecer uma fórmula aditiva para obtenção de uma avaliação global.

A Figura 2 apresenta as etapas da pesquisa realizadas neste trabalho. Essas etapas contemplam os passos da abordagem multicritério propostos acima.

A etapa 1 envolveu a identificação, a formulação e o entendimento do problema a ser estudado, tendo em vista a relevância do mesmo para a empresa.

A etapa 2 compreendeu a construção do embasamento teórico do estudo acerca de dois temas principais: o problema da seleção de fornecedores (SSP) e a modelagem multicritério de apoio à decisão.

No que tange à etapa 3 , foram definidos os objetivos pretendidos e as ferramentas para a aplicação metodológica.

A etapa 4 abrangeu a aplicação propriamente dita do modelo de avaliação, no caso, a modelagem multicritério de apoio à decisão, sendo composta por quatro etapas, que se segmentam em algumas outras. Para essas etapas, o roteiro apresentado no Anexo A foi utilizado. Foram realizadas diversas visitas à empresa a fim de entender como se dava o processo de seleção de fornecedores.

A priori, na etapa 4.1 foi realizada uma visita à empresa e uma entrevista com o gerente do setor de compras, na qual se definiu o rótulo do problema, ou seja, o questionamento que este trabalho ajudaria a responder, como já citado anteriormente.

Em seguida, na etapa 4.2, baseando-se nas informações obtidas na entrevista foi montada a árvore de decisão com os pontos de vista fundamentais (PVFs), ou seja, os aspectos considerados relevantes para o decisor na seleção de um fornecedor. Para cada um deles foram definidos os pontos de vista elementares (PVEs), que representam os aspectos que são avaliados dentro de cada PVF.

Na etapa 4.3 foram elaborados os descritores para cada um dos PVEs, que correspondem a um conjunto de descrições que possibilitam ao decisor identificar o nível de impacto de uma ação. lsso tem por objetivo mensurar a performance de cada fornecedor avaliado com relação ao critério analisado.

$\mathrm{Na}$ etapa 4.4 foram obtidas as funções de valor para as preferências do decisor, que quantificaram o desempenho de cada fornecedor com relação aos PVFs e PVEs analisados.

Na seção seguinte o processo de avaliação de fornecedores foi aplicado e validado, com o objetivo de identificar a melhor opção entre os fornecedores. Para a validação qualitativa do modelo, o roteiro apresentado no Anexo B foi utilizado.

\section{Estruturação do modelo multicritério}

\subsection{Caracterização da empresa objeto de estudo}

Este trabalho foi realizado em uma empresa do segmento de implementos rodoviários de transporte de carga que atua no mercado há mais de 30 anos.

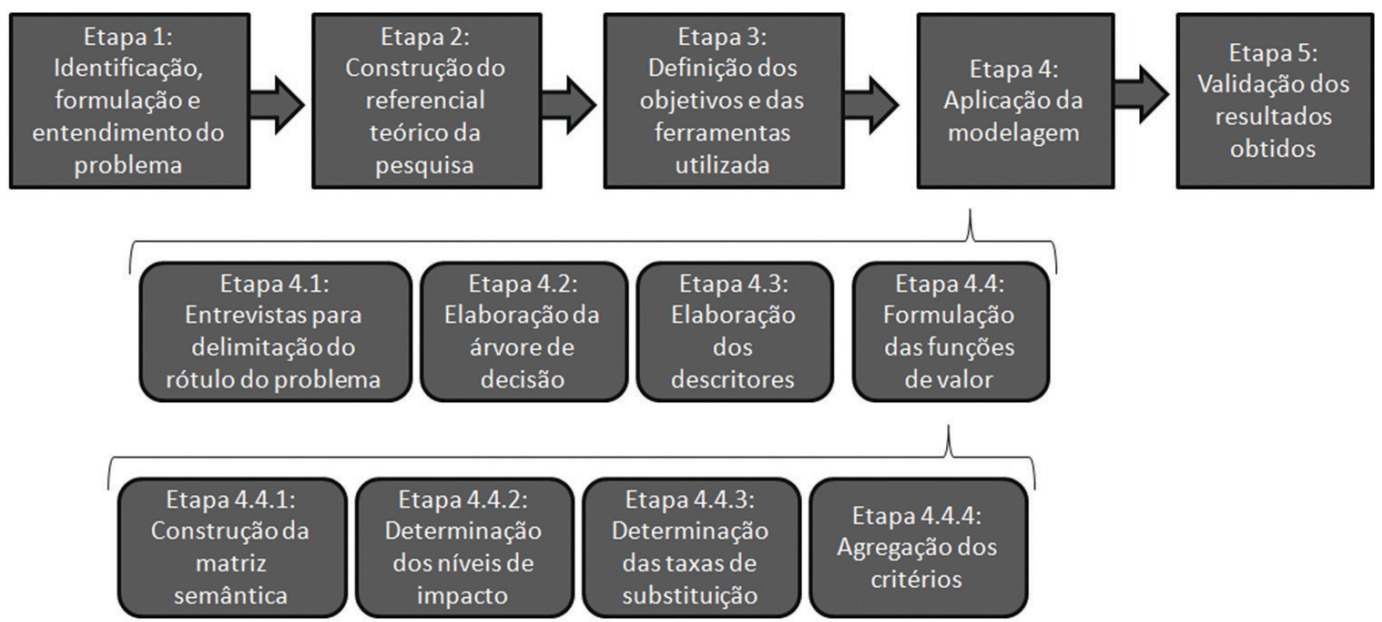

Figura 2. Etapas para realização do estudo proposto. 
Alguns dos implementos fabricados pela empresa são: caçamba semirreboque estilo meia-cana e standard; furgão sobre chassi baú; carroceria para transporte de bebidas e carroceria carga seca grade alta. Em 2011, o percentual das vendas distribuiu-se da seguinte maneira: as caçambas representaram 35\% das vendas, seguidas pelas carrocerias, com 31\%, baús, 27\% e semirreboques, 7\% (dados obtidos por meio de análise documental).

A relação que a empresa cultiva com seus fornecedores é puramente comercial, o que faz com que leve em consideração os fatores relacionados à sua operação. Devido a esse fato, alguns fatores apresentados por Guarnieri dos Santos (2012) não foram levados em consideração na realização da avaliação. Esse tipo de relacionamento implica em um problema relacionado à qualidade do produto e à confiabilidade na entrega, principalmente.

\subsection{Descrição do contexto do problema de decisão}

A seleção de fornecedores das matérias-primas necessárias à produção dos implementos era realizada de forma empírica, baseando-se somente na avaliação do gerente do setor de compras, por meio de sua experiência (considerado o decisor do processo). Os demais atores envolvidos no processo de avaliação de fornecedores são os colaboradores da empresa e os próprios fornecedores, além do pesquisador.

Como se tem conhecimento da inviabilidade de aplicação da avaliação para todos os fornecedores das matérias-primas, dado que para a fabricação de cada um dos implementos citados anteriormente são necessários mais de 100 componentes, além da grande quantidade de tempo que a construção desse modelo demandaria por parte do decisor e do pesquisador e do pouco tempo disponível para sua realização, optou-se por avaliar os fornecedores para um componente que representasse investimento elevado em recursos para a empresa. Buscando visualizar qual seria esse material, elaborou-se a curva $A B C$ de materiais.

Dentre as matérias-primas mais importantes, a chapa de aço foi escolhida como objeto de estudo por ser indispensável para a fabricação de todos os implementos abordados. Com isso, definiu-se como rótulo do problema: A construção de um modelo multicritério para avaliação de fornecedores de chapa de aço de uma empresa fabricante de implementos rodoviários.

\subsection{Mapas cognitivos e pontos de vista fundamentais}

Foram feitas visitas à empresa para a realização de entrevistas com o gerente por meio do roteiro apresentado no Anexo A. Apesar da decisão sobre o que comprar e de quem comprar ser baseada somente na sua experiência, o gerente elencou alguns critérios por ele considerados de grande relevância no momento da tomada de decisão, descritos no tópico a seguir. É importante ressaltar o fato de que o gerente iria sair da empresa em breve e, caso esse conhecimento não fosse mapeado, representaria uma grande perda para a organização estudada, pois o gerente que 0 substituirá não o detém.

Assim, em função das respostas obtidas por meio do roteiro de entrevista apresentado no Anexo A, foi elaborada uma estrutura arborescente para auxiliar o agrupamento desses fatores de acordo com seu nível de relação. Nessa estrutura estão descritos o rótulo do problema e representados os Pontos de Vistas Fundamentais (PVFs) e os Pontos de Vista Elementares (PVEs), como pode ser visualizado na Figura 3.

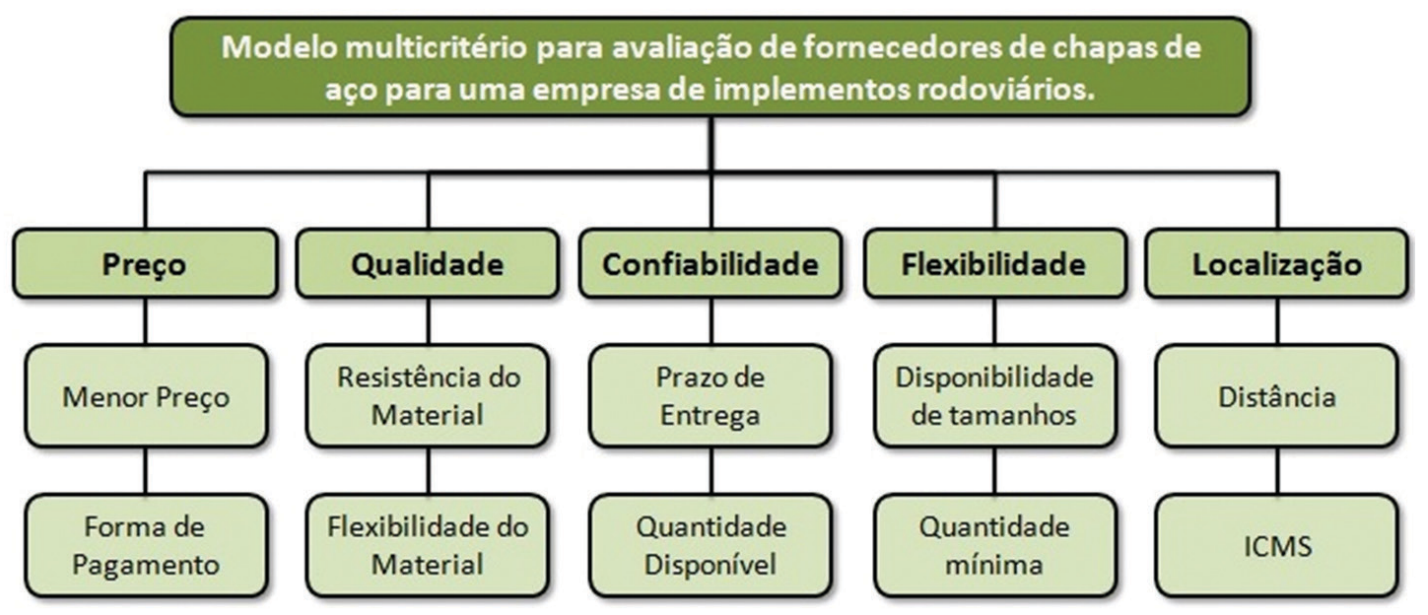

Figura 3. Estrutura arborescente do modelo. Fonte: elaborada pelos autores (2013). 
Pela Figura 3 constata-se a existência de cinco critérios para análise do fornecedor (pontos de vista fundamentais - PVFs), que agregam outros dez subcritérios (pontos de vista elementares - PVEs). A Tabela 2 apresenta a descrição desses subcritérios, bem como sua lógica (minimização ou maximização) e escala (qualitativa ou quantitativa).

Todos os critérios considerados relevantes para realização desse processo de seleção e avaliação de fornecedores constam no levantamento realizado nas pesquisas de Dickson (1966), Stavropolous (2000) e Guarnieri dos Santos (2012), referenciados no embasamento teórico deste trabalho.

\subsection{Construção dos descritores}

Definida a estrutura arborescente e seus Pontos de Vista Fundamentais e Elementares, pôde-se iniciar a construção do modelo de seleção de fornecedores da empresa. 0 primeiro passo foi a proposição dos descritores, caracterizada pela construção de escalas ordinais que proporcionam um melhor entendimento do que representam aqueles critérios mensurados.

Foram identificados dez critérios que os fornecedores devem atender. Para cada um deles foram elaborados descritores com seus níveis de impacto. Na Figura 4 são apresentados os descritores devidamente normatizados.

0 primeiro descritor é o PVE Menor preço oferecido pelo fornecedor. Nesse caso, do ponto de vista da empresa era mais interessante comprar a matéria-prima a um preço mais barato, no caso entre $R \$ 250,00$ e R\$280,00, pois, segundo o conceito de Margem de Contribuição Unitária, diminuindo-se os custos variáveis (custos com matéria-prima e/ou mão de obra), colabora-se para o aumento da lucratividade da empresa.

0 segundo é o PVE Forma de pagamento oferecida pelo fornecedor. Nesse ponto a empresa preferia realizar os pagamentos em três parcelas para 30, 45 e 60 dias, pois o valor liquidado na compra das chapas só será capitalizado após a venda dos implementos. Assim, quando há um prazo maior para efetuar o pagamento, a empresa permanece com capital de giro para investir em outros aspectos que julgue necessários naquele momento.

Em seguida tem-se a Resistência do material propiciada pelo fornecedor. Nesse ponto era importante para a empresa que as chapas de aço fossem resistentes, devido à natureza dos implementos rodoviários que

Tabela 2. Descrição dos Pontos de Vista Elementares.

\begin{tabular}{|c|c|c|c|c|}
\hline & Critérios & Descrição & Lógica & Escala \\
\hline \multicolumn{5}{|c|}{ Ponto de Vista Fundamental: Preço } \\
\hline \multirow{2}{*}{ PVEs } & Menor preço & $\begin{array}{l}\text { Menor preço oferecido pelos } \\
\text { fornecedores }\end{array}$ & Minimizar custos & Quantitativa \\
\hline & Forma de pagamento & $\begin{array}{l}\text { Maior prazo de pagamento } \\
\text { oferecido pelos fornecedores }\end{array}$ & Maximizar o capital de giro & Quantitativa \\
\hline \multicolumn{5}{|c|}{ Ponto de Vista Fundamental: Qualidade } \\
\hline \multirow{2}{*}{ PVEs } & Resistência do material & Dureza da chapa & $\begin{array}{l}\text { Maximizar a resistência da } \\
\text { chapa }\end{array}$ & Qualitativa \\
\hline & Flexibilidade da chapa & Flexibilidade da chapa & $\begin{array}{l}\text { Maximizar a flexibilidade das } \\
\text { chapas }\end{array}$ & Qualitativa \\
\hline \multicolumn{5}{|c|}{ Ponto de Vista Fundamental: Confiabilidade } \\
\hline \multirow{2}{*}{ PVEs } & Prazo de entrega & $\begin{array}{l}\text { Fornecedor com menor prazo } \\
\text { de entrega }\end{array}$ & Minimizar o tempo de entrega & Quantitativa \\
\hline & Quantidade disponível & $\begin{array}{c}\text { Capacidade de o fornecedor } \\
\text { atender a demanda da empresa }\end{array}$ & $\begin{array}{c}\text { Maximizar a disponibilidade } \\
\text { de chapas }\end{array}$ & Qualitativa \\
\hline \multicolumn{5}{|c|}{ Ponto de Vista Fundamental: Flexibilidade } \\
\hline \multirow{2}{*}{ PVEs } & Disponibilidade de tamanhos & $\begin{array}{c}\text { Fornecedor que possua os } \\
\text { tamanhos de chapa dos quais a } \\
\text { empresa necessita }\end{array}$ & $\begin{array}{l}\text { Maximixar a variedade de } \\
\text { tamanhos }\end{array}$ & Quantitativa \\
\hline & $\begin{array}{l}\text { Quantidade mínima para fechar } \\
\text { o pedido }\end{array}$ & $\begin{array}{c}\text { Fornecedor que aceite pedidos } \\
\text { com qualquer quantidade de } \\
\text { chapas }\end{array}$ & $\begin{array}{c}\text { Minimizar a quantidade } \\
\text { mínima }\end{array}$ & Quantitativa \\
\hline \multicolumn{5}{|c|}{ Ponto de Vista Fundamental: Localização } \\
\hline \multirow[b]{2}{*}{ PVEs } & Distância & $\begin{array}{c}\text { Fornecedor com menor } \\
\text { distância em relação à empresa }\end{array}$ & Minimizar a distância & Quantitativa \\
\hline & ICMS & $\begin{array}{l}\text { Menor diferença entre o ICMS } \\
\text { do estado do fornecedor e o } \\
\text { da empresa }\end{array}$ & Minimizar a diferença de ICMS & Quantitativa \\
\hline
\end{tabular}

Fonte: elaborada pelos autores (2013). 
fabrica, por exemplo, as caçambas utilizadas para transportar toneladas de materiais como areia, pedras, britas, entre outros.

Já no descritor Flexibilidade do material vendido pelo fornecedor, o importante, como o próprio termo deixa claro, era que as chapas também fossem flexíveis, para que pudessem ser moldadas pela máquina de corte e dobra e, assim, fabricados bases e quadros para o

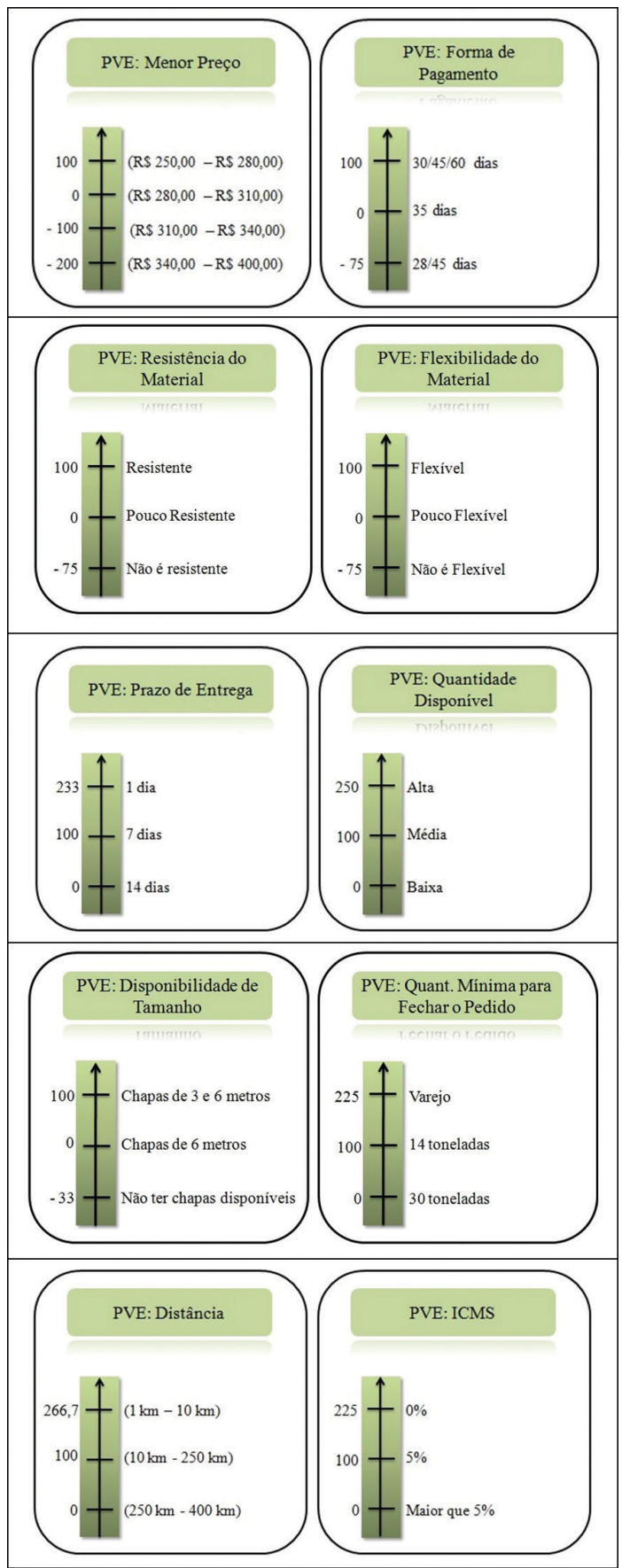

Figura 4. Descritores. Fonte: elaborada pelos autores (2013). baú, perfis laterais e traseiros para carrocerias, chassi, cocho e acessórios para caçamba, indispensáveis na produção dos implementos.

No descritor Prazo de entrega foram apresentados os prazos de entrega das chapas de aço usualmente aplicados pelos fornecedores. Obviamente, era preferível para a empresa o prazo de um dia, pois comprando e recebendo as chapas no mesmo dia elas já eram encaminhadas para a produção, não gerando estoque nem ocupando espaço físico.

O descritor Quantidade disponível mostra a capacidade de os fornecedores atenderem a demanda da empresa. Nesse ponto era importante para a empresa que os fornecedores tivessem alta disponibilidade de chapas, para que pudessem atender ao seu pedido.

0 descritor Disponibilidade de tamanho mostra os tipos de chapas que cada fornecedor dispõe. Para a empresa, o fato de o fornecedor possuir os dois tamanhos de chapa era melhor, porque suas máquinas são projetadas para trabalhar com chapas de 3 metros. Caso o fornecedor só tivesse chapas de 6 metros, a empresa ainda teria que cortá-las antes de introduzi-las no processo produtivo.

No descritor Quantidade mínima para fechar o pedido são apresentadas as quantidades mínimas que os fornecedores exigem sejam compradas para que o pedido possa ser fechado. No caso, as 14 toneladas correspondem a um caminhão truck completamente carregado e as 30 toneladas, a uma carreta. Obviamente, a opção de varejo era a preferivel para a empresa, assim, ela comprava apenas a quantidade de chapas que necessitava no momento, não gerando estoques por comprar mais do que fosse preciso.

0 descritor Distância mostra a distância que separam fornecedores e empresa consumidora. Por questões de tempo de entrega, frete, falhas na programação de produção e a necessidade de ter aquela matéria-prima imediatamente, a baixa distância, de 1 $\mathrm{km}$ a $10 \mathrm{~km}$, foi escolhida como a melhor pelo decisor.

No descritor ICMS, os níveis de impacto são representados pelas diferenças entre o imposto de alguns estados nos quais se localizam os fornecedores, por exemplo, o nível de impacto 0\% significa que a empresa que fornece as chapas está situada no mesmo estado da empresa que as compra, ou seja, não há diferença entre o ICMS cobrado, pois ambas estão situadas no RN. Já o nível de impacto 5\% mostra que a diferença entre o ICMS do estado em que estão os fornecedores e o do estado em que está comprador é de 5\%, no caso, uma empresa localizada no Rio Grande do Norte (ICMS de 12\%) e um fornecedor de Fortaleza (ICMS de 17\%). É evidente que para a empresa era preferivel que a diferença de ICMS fosse 
de $0 \%$, pois isso significa que não há necessidade de pagar esse imposto, pois as empresas estão localizadas no mesmo estado, como já explicado.

\section{Fase de avaliação do modelo multicritério proposto}

\subsection{Taxas de substituição}

Para obtenção das taxas de substituição (pesos), recorreu-se a procedimentos parecidos com os empregados na obtenção de níveis de impacto, com pequenas diferenças (item 6 do Anexo A).

Para obtenção das taxas de substituição dos pontos de vista fundamentais o mesmo procedimento foi realizado. A ordem de importância dos critérios para a seleção de fornecedores de chapa de aço para a empresa foi obtida da seguinte maneira: o critério preço era mais importante que qualidade, que por sua vez era preferivel a confiabilidade, a qual era mais importante que flexibilidade, que superava a relevância do critério localização. A Tabela 3 apresenta as taxas obtidas por meio do juízo de valor do decisor.

\subsection{Função de valor}

Tendo sido obtidos os valores dos níveis de impacto e as taxas de substituição de cada um dos pontos de vista elementares, foi possível construir uma função de valor para cada um desses pontos de vista. A função de valor foi obtida por meio das respostas do decisor ao item 6 do roteiro de entrevista, que pode ser visualizado no Anexo A. A Equação 1 apresenta a fórmula de agregação aditiva.

$$
A g=\sum_{j=1}^{n} \text { Fj.wj. }\left(\sum_{i=1}^{k} C i . B i\right)
$$

Em que: $\mathrm{Ag}=$ avaliação global do fornecedor; $F j=$ fator de índice $j ; \mathrm{Wj}=$ peso do fator $\mathrm{j} ; \mathrm{n}=$ número de PVF; $\mathrm{Ci}=$ valor do nível de impacto no PVE i;
$\mathrm{Bi}=$ valor do peso atribuído ao PVE $\mathrm{i}$; e $\mathrm{k}=$ número de PVE por PVF.

\subsection{Validação do modelo}

Segundo o gerente do setor de compras, a empresa trabalhava apenas com cinco fornecedores: um localizado na cidade de Mossoró, onde está localizada também a matriz da empresa; dois em Fortaleza, onde a empresa possui filial; e dois em Recife. Portanto, o modelo se restringiu a eles.

A Tabela 4 apresenta a avaliação do fornecedor 1 quanto a cada critério separadamente, bem como a sua avaliação global. 0 mesmo foi feito para os outros quatro fornecedores.

Por meio da Figura 5 é possível verificar que o fornecedor 1 se destaca no critério confiabilidade, apresentando um boa performance no quesito qualidade, desempenho mediano nos atributos flexibilidade e localização e desempenho negativo referente a preço.

Observando-se a Figura 6 constata-se que o fornecedor 2 apresenta qualidade elevada, porém é mal avaliado nos critérios flexibilidade e localização. No aspecto confiabilidade apresenta desempenho aceitável e no quesito preço é considerado com desempenho abaixo do esperado por cobrar preço um pouco alto pela sua mercadoria.

Na Figura 7, o fornecedor 3 mostra-se superior no quesito qualidade, além de ter bom desempenho nos critérios de confiabilidade e preço. 0 maior problema que a empresa de implementos rodoviários encontra em trabalhar com esse fornecedor é a sua localização, sendo o prazo de entrega do produto estipulado em cerca de 15 dias.

0 fornecedor 4, desempenho apresentado na Figura 8, é avaliado negativamente quanto ao critério preço, por ser o mais alto entre os de todos os fornecedores, quanto à qualidade e confiabilidade,

Tabela 3. Taxas de substituição.

\begin{tabular}{lclc}
\hline Pontos de Vista Fundamentais & Taxa de substituição & Pontos de Vista Elementares & Taxa de substituição \\
\hline \multirow{2}{*}{ Preço } & $36,36 \%$ & Menor preço & $69,23 \%$ \\
& & Forma de pagamento & $30,77 \%$ \\
Qualidade & $24,24 \%$ & Resistência do material & $71,43 \%$ \\
& & Flexibilidade do material & $28,57 \%$ \\
Confiabilidade & \multirow{2}{*}{$18,18 \%$} & Prazo de entrega & $62,50 \%$ \\
& \multirow{2}{*}{ Flexibilidade } & Quantidade disponível & $37,50 \%$ \\
& \multirow{2}{*}{ Localização } & Disponibilidade de tamanhos & $58,33 \%$ \\
& \multirow{2}{*}{$6,06 \%$} & Quantidade mínima para fechar o pedido & $41,67 \%$ \\
\hline
\end{tabular}


demonstra uma boa performance. Quanto à localização, é superado por fornecedores mais próximos.

Na Figura 9, observa-se que o fornecedor 5 apresenta uma avaliação ótima quanto a preço, no limite quanto à qualidade, boa no que diz respeito a confiabilidade e sua flexibilidade e localização são consideradas razoável e boa, respectivamente.

Na Figura 10 procurou-se analisar em um único gráfico todos os fornecedores de chapa da indústria de implementos rodoviários, a fim de confrontá-los com

Tabela 4. Avaliação do fornecedor 1.

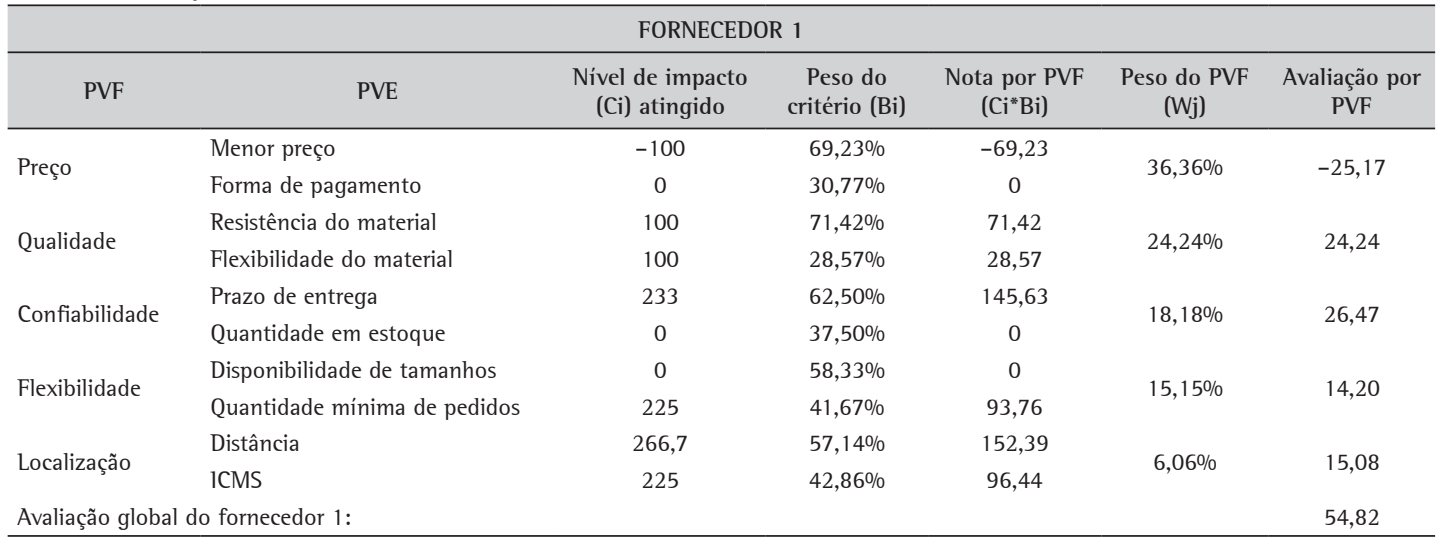

Fonte: autores (2013).

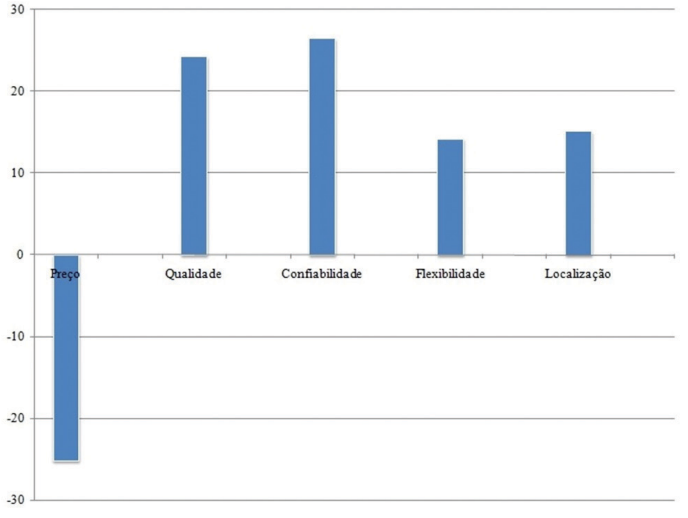

" Avaliação do Fom 1

Figura 5. Avaliação do fornecedor 1.

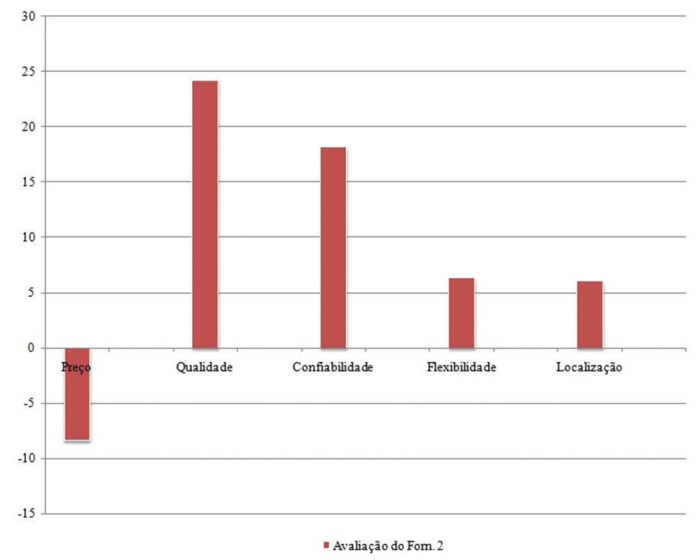

Figura 6. Avaliação do fornecedor 2.

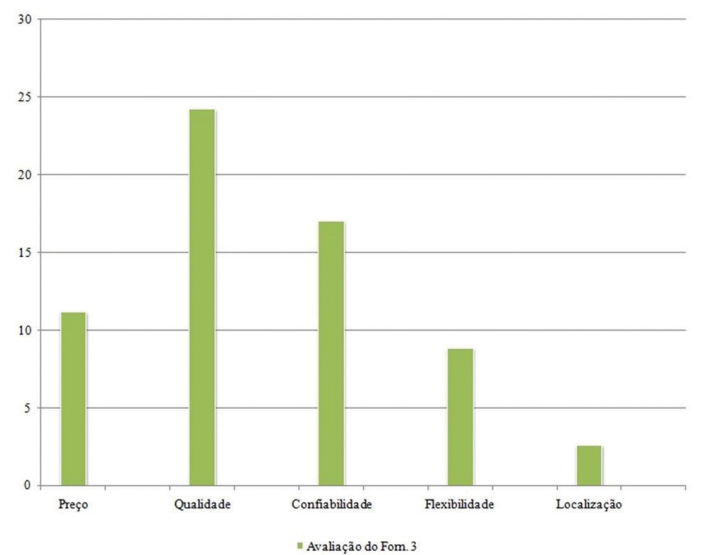

Figura 7. Avaliação do fornecedor 3.

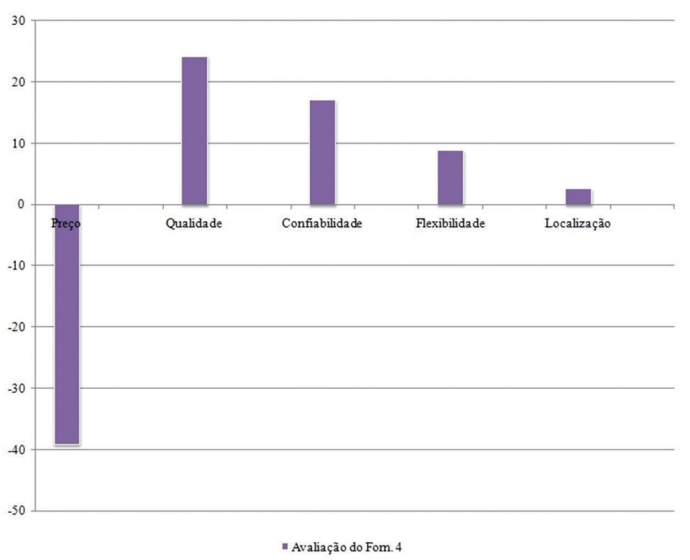

Figura 8. Avaliação do fornecedor 4. 


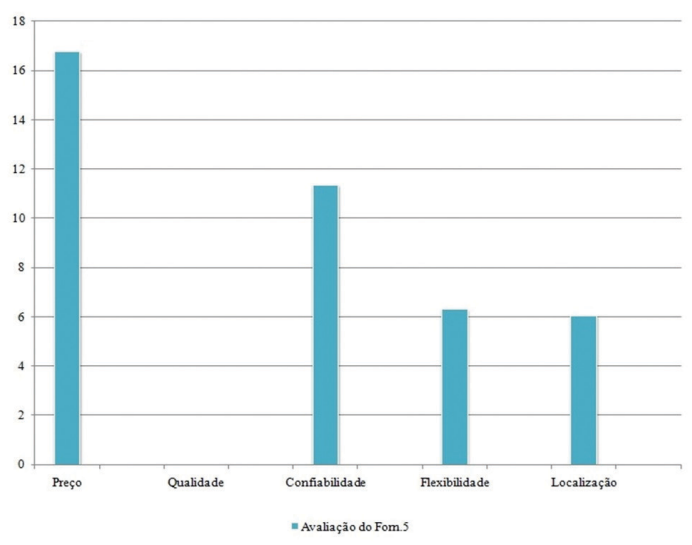

Figura 9. Avaliação do fornecedor 5.

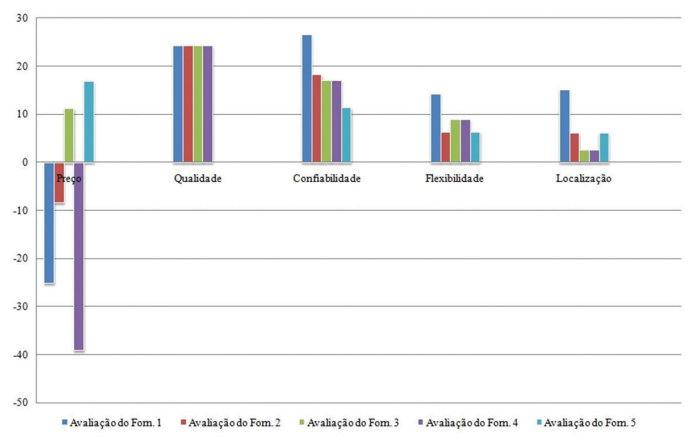

Figura 10. Comparativo das notas de avaliação dos fornecedores.

relação aos pontos de vista fundamentais e verificar qual dentre eles apresentava o melhor desempenho com relação a cada critério.

Por meio da Figura 10 pôde-se analisar qual dentre os fornecedores estudados apresentava melhor desempenho quanto a determinados critérios. Assim, concluiu-se que em relação ao PVF Preço, o fornecedor 5 apresentava melhor performance e o fornecedor 4 , a pior.

Já no que diz respeito ao PVF qualidade, dos cinco fornecedores estudados, quatro encontravam-se empatados quanto a esse quesito e a performance menos atrativa associava-se ao fornecedor 5 .

Analisando-se o atributo Confiabilidade, constatou-se que o fornecedor 1 possuía a performance mais atrativa, seguido pelo fornecedor 2. Os fornecedores 3 e 4 estavam empatados e o 5, mais uma vez, apresentou o desempenho menos atrativo.

Quanto ao critério Flexibilidade, o fornecedor 1 mostrou ter um grau de atratividade bastante superior aos demais. Os fornecedores 3 e 4 empataram nesse critério, sendo considerados como razoavelmente atrativos. Os fornecedores 2 e 5 também empataram nesse critério, sendo considerados pouco atrativos.
Em relação ao PVF Localização, o grau de atratividade do fornecedor 1 em relação aos outros foi extremo, pois essa empresa localizava-se a uma distância mínima da indústria de implementos rodoviários. Nesse quesito, mais uma vez houve empate entre os fornecedores 2 e 5 e entre os fornecedores 3 e 4, justificado pelo fato de essas duplas estarem localizadas na mesma cidade.

Posteriormente à visualização do desempenho de cada um dos fornecedores de forma individual foi possível fazer uma comparação entre eles observando-se cada um dos critérios. Entre os fornecedores analisados, o que apresentou o melhor desempenho global foi o fornecedor 3. Entretanto, constata-se que esse fornecedor, apesar de não ter superado os outros em nenhum critério, manteve seu bom desempenho em todos.

A empresa comprava chapas de aço dos fornecedores 3 e 1 , os quais obtiveram, respectivamente, a primeira e a segunda melhores avaliações globais, como já foi dito. Contudo, essa decisão era baseada exclusivamente na análise empírica do gerente.

A escolha do decisor em negociar com o fornecedor 3 , baseada em sua vivência na empresa, deu-se por ele considerar que os produtos feitos com as chapas de aço desse fornecedor tinham menor chance de amassar, ou seja, melhor qualidade, e, também, por esse fornecedor ter um bom preço.

0 fornecedor 3 demorava em média 15 dias para entregar as chapas. A empresa, porém, não podia esperar tanto tempo, pois não possuía um controle de estoque eficiente - devido à grande quantidade e intensa movimentação de materiais, a falta de um material só era percebida quando ele era necessário na linha de produção.

Então, com o objetivo de minimizar as paradas na produção ocasionadas pela falta de chapas de aço, o gerente de suprimentos optava por comprá-las do fornecedor 1 que, apesar de cobrar um preço mais alto, conseguia entregá-las em um dia, ou seja, nesse momento o critério ganhador de pedido era o prazo de entrega.

Por meio da avaliação de fornecedores realizada, a empresa pôde visualizar o quão melhor é comprar de um fornecedor em relação a outro e, fundamentada nesse modelo, busca aprimorar o seu controle de estoque.

Com os resultados da avaliação, o pesquisador retornou à empresa e realizou uma entrevista (baseado no roteiro de entrevista apresentado no Anexo B) visando a validação do modelo.

Por meio das respostas do gerente aos questionamentos, pode-se afirmar que o modelo proposto representou de forma apropriada a situação 
problema, relacionando os critérios corretamente e contribuindo para a reflexão acerca de possíveis soluções.

Ao analisar o processo de avaliação, o decisor não identificou nenhum outro critério que pudesse ser acrescentado. Também declarou que uma das vantagens do modelo foi demonstrar em quais aspectos e o quanto um fornecedor era melhor que o outro podendo, assim, unir essas informações à sua experiência para tomar decisões acertadas. Como desvantagem, o gerente relatou dificuldade no entendimento referente à construção do processo avaliativo.

\section{Conclusões}

A avaliação de fornecedores é, de fato, um processo de extrema relevância dentro de qualquer organização. Esse processo deve ser claro e com os procedimentos bem definidos. Por isso, é pertinente afirmar que a utilização de uma ferramenta que permita apoiar a decisão de forma sistemática, interativa e rápida é uma alternativa para se aperfeiçoar esse processo.

A abordagem multicritério possui potencial para a transformação do conhecimento tácito, detido pelo gerente sobre a seleção de fornecedores, em conhecimento explícito para a organização, pois 0 processo de formalização do conhecimento, ou seja, conversão do conhecimento tácito em explícito, por meio do diálogo e documentação, é essencial para proporcionar o entendimento comum do problema, apoiar o processo de geração dos critérios e, por meio da sistematização e aplicação do conhecimento explícito, servir de base para a avaliação do desempenho dos fornecedores.

A principal vantagem observada na utilização da abordagem multicritério decorre da possibilidade de construir um modelo de valores quantitativos (numéricos) baseados em julgamentos comparativos qualitativos (não numéricos), recorrendo a escalas de valor relacionadas com a diferença de atratividade das diferentes opções.

Essa abordagem permitiu realizar uma avaliação global dos fornecedores, englobando todos os critérios avaliados (preço, qualidade, confiabilidade, flexibilidade e localização), mostrando qual dentre todos os critérios apresentava melhor desempenho de forma geral, o que evidencia que o objetivo proposto foi alcançado.

Após a realização do processo de avaliação de fornecedores, foram apresentados os resultados para a empresa e o fornecedor que obteve melhor desempenho global quanto aos critérios relacionados pela empresa foi o fornecedor 3. Porém, para comprar as chapas de aço desse fornecedor é necessário que o pedido seja de 30 toneladas (uma carreta cheia) e que ele seja feito com no mínimo 15 dias de antecedência, pois esse é o seu prazo de entrega. Para que seja possível solicitar esses pedidos, é necessário que haja uma programação prévia. A empresa estudada, contudo, ainda está passando por um processo de implantação de técnicas de planejamento e programação da produção. Devido a esse motivo, a empresa optava por comprar, por enquanto, do fornecedor 1, pois só comprava o que era necessário para aquele dia.

Uma contribuição desta pesquisa reside na demonstração de um caso de sucesso da utilização da abordagem MCDA como ferramenta para a transformação do conhecimento tácito em conhecimento explícito, representada pela formalização do conhecimento de um conjunto de atores, o que representa um ganho para a organização, pois as informações detidas pelo grupo passaram a ser de posse da empresa, estando disponíveis a qualquer momento, independentemente de quem comandar o departamento de compras.

Dentre as limitações da pesquisa, identificamos que a utilização da abordagem MCDA utilizada isoladamente não responde a todos os anseios das organizações, sendo necessária a integração dessa abordagem com os métodos de otimização tradicionais para a estruturação de uma cadeia de suprimentos mais eficiente.

Em pesquisas futuras sugere-se a integração dessa abordagem de avaliação de fornecedores a um modelo de otimização, com o intuito de observar o impacto desse tipo de abordagem no custo de transporte da cadeia de suprimentos.

\section{Referências}

Alencar, L. H., Almeida, A. T., \& Mota, C. M. M. (2007). Sistemática proposta para seleção de fornecedores em gestão de projetos. Gestão \& Produção, 14(3), 477-487. http://dx.doi.org/10.1590/S0104-530X2007000300005

Alencar, L. H., \& Almeida, A. T. (2008). Multicriteria decision group model for the selection of suppliers. Revista Pesquisa Operacional, 28(2). http://dx.doi.org/10.1590/ S0101-74382008000200009

Balestrin, A., \& Verschoore, J. (2008). Redes de cooperação empresarial. Porto Alegre: Editora Bookman.

Carmo, B. B. T., Barros Neto, J. F., \& Dutra, N. G. S. (2011). Análise dos impactos nos custos de transportes de um modelo de seleção de fornecedores baseado em variáveis socioambientais e de competitividade. Produção, 21(3), 466-483. http://dx.doi.org/10.1590/ S0103-65132011005000013

Chen, Y., Kilgour, D. M. E., \& Hipel, K. W. (2013). An integrated approach to multiple criteria decision aid: consequence-based preference aggregation. Retrieved from http://www.ibrarian.net/navon/paper/ An_integrated_approach_to_multiple_criteria_decis. pdf?paperid $=9015038$ 
Cheraghi, S. H., Dadashzadeh, M., \& Subramanian, M. (2004). Critical success factors for supplier selection: an update. Journal of Applied Business Research, 20(2), 91-108.

Costa, J. F. S., Brazil, C. H. A., \& Olivera, M. B. (2003). Metodologia multicritério e ECR: utilização no mercado varejista. Produção, 13(20). http://dx.doi.org/10.1590/ S0103-65132003000200011

De Boer, L., Labro, E., \& Morlacchi, P. (2001). A review of methods supporting supplier selection. European Journal of Purchasing and Supply Management, 7(2), 75-89. http://dx.doi.org/10.1016/S0969-7012(00)00028-9

Dickson, G. W. (1966). An analysis of vendor selection systems and decisions. Journal Purchasing, 15-17.

Ensslin, L., Giffhorn, E., Ensslin, S. R., Petri, S. M., \& Vianna, W. B. (2010). Avaliação do Desempenho de Empresas Terceirizadas com o uso da Metodologia Multicritério em Apoio à Decisão - Construtivista. Pesquisa Operacional, 30(1), 125-152. http://dx.doi.org/10.1590/ S0101-74382010000100007

Gil, A. C. (2002). Como elaborar projetos de pesquisa (4. ed.). São Paulo: Atlas.

Guarnieri dos Santos, P. (2012). Modelo de apoio à decisão multicritério para classificação de fornecedores em níveis de colaboração no gerenciamento da cadeia de suprimentos utilizando o método ELECTRE TRI (Tese de doutorado). Universidade Federal de Pernambuco, Recife. Retrieved from www.ppgep.org.br/downloadDoc. php?d...f...patricia....

Hammond, J. S., Kenney, R. L., \& Raiffa, H. (1999). Smart Choices A Practical Guide to Making BetterDecisions. Harvard Business School Press, Boston.

Ha, S. H., \& Krishnan, R. (2008). A hybrid approach to supplier selection for the maintenance of a competitive supply chain. Expert Systems with Applications, 34(2), 13031311. http://dx.doi.org/10.1016/j.eswa.2006.12.008

Keeney, R. L., \& Raiffa, H. (1976). Decision with multiple objectives: preferences and value tradeoffs. John Wiley \& Sons.
Luo, X., Wu, C., Rosenberg, D., \& Barnes, D. (2009). Supplier selection in Agile Supply Chains: An Informationprocessing Model and lllustration. Journal of Purchasing \& Supply Management, 15(4), 249-262. http://dx.doi. org/10.1016/j.pursup.2009.05.004

Marconi, M. A., \& Lakatos, E. M. (2003). Fundamentos de metodologia científica (5. ed.). São Paulo: Atlas.

Miguel, P. A. C., Fleury, A., Mello, C. H. P., Nakano, D. N., Lima, E. P., Turroni, J. B., Ho, L. L., Morabito, R., Martins, R. A., Sousa, R., Costa, S. E. G., \& Pureza, V. (2012). Metodologia de Pesquisa em Engenharia de Produção e Gestão de Operações (2. ed.). Rio de Janeiro: Elsevier; ABEPRO.

Nonaka, 1., \& Takeuchi, H. (1995). The Knowledge-creating Company: How Japanese Companies Create the Dynamics of Innovation. New York: Oxford University Press.

Oliveira, R. C., \& Lourenço, J. C. (2002). A multi-criteria model for assigning new orders to service suppliers. European Journal of Operations Research, 139(2). http:// dx.doi.org/10.1016/S0377-2217(01)00367-8

Rauscher, H. M., Schmoldt, D. L., \& Vacik, H. (2007). Information and Knowledge Management in Support of Sustainable Forestry: A Review. In K. M. Reynolds, M. Kohl, A. Thomson, M. A. Shannon, D. Ray \& K. Rennolls (Eds.), Sustainable Forestry: from Monitoring and Modelling to Knowledge Management and Policy Science. Wallingford: CABl. Retrieved from http:// http:// www.treesearch.fs.fed.us/pubs/results.php.

Stavropolous, N. (2000). Suppliers in the new economy. Telecomunications Journal of Australia, 50(4), 27-29.

Sonmez, M. (2006). A Review and Critique of Supplier Selection Process and Pratices. Business School Occasional Papers Series, Paper 2006:1. Loughborough: Loughborough University.

Weber, C. A., Current, J. R., \& Benton, W. C. (1991). Vendor selection criteria and methods. European Journal of Operational Research, (50). http://dx.doi. org/10.1016/0377-2217(91)90033-R

Yin, R. K. (2001). Estudo de caso - planejamento e métodos. (2nd ed.). Porto Alegre: Bookman.

\title{
MCDA based evaluation of steel plate suppliers in the auto industry
}

\begin{abstract}
In many cases, business managers rely on experience to evaluate or select suppliers. This can lead to imprecise evaluations because there are many alternatives that can sometimes can be conflicting, depending of the criteria. This study focused on a road equipment factory located in the west of Rio Grande do Norte, which has encountered some problems with suppliers of steel plates, the main raw material required for road equipment production. We attempted to evaluate the suppliers of steel plates using the MCDA approach. With this approach, it was possible to evaluate the performance of suppliers individually for each criterion established by the company. Overall, we were able to identify which of the suppliers would be the best choices for the company. We also found that the MCDA approach can be used to transform tacit knowledge into explicit knowledge for use in enterprises.
\end{abstract}

Keywords

Road equipment industry. Supplier selection problem. Multicriteria Decision Aid. 


\section{Anexo A. Roteiro de entrevista - Fase 1.}

\begin{tabular}{|l|l|}
\hline Roteiro de entrevista & Cargo: \\
\hline Preenchido por: & Data: \\
\hline Empresa: &
\end{tabular}

Definido o rótulo do problema, são feitos os seguintes questionamentos:

Quais critérios são levados em consideração no processo de avaliação de fornecedores?

Qual a ordem de importância entre esses critérios? (Por exemplo, o critério Preço é mais importante que o critério Qualidade, que é mais importante que o Prazo de entrega e assim por diante?)

Quais fatores são analisados dentro de cada um desses critérios? (Por exemplo, dentro do critério Preço, analisam-se as formas de pagamento, entre outros fatores?)

Com base nas questões acima é possível construir junto ao entrevistado a árvore de decisão.

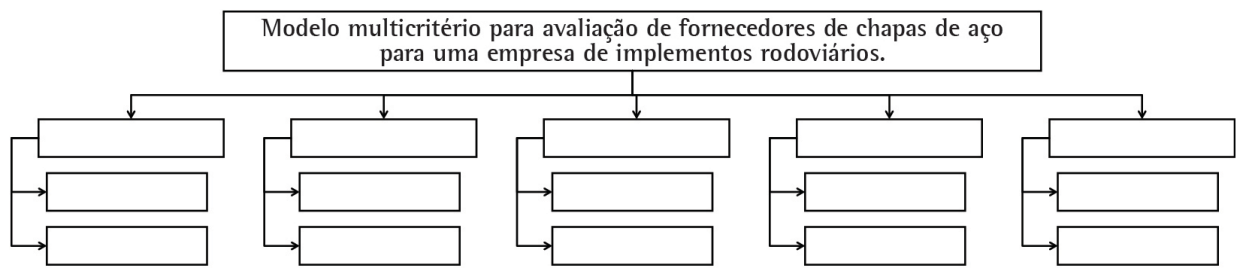

0 próximo passo é a construção dos descritores. Para isso são feitos os seguintes questionamentos para cada um dos critérios:

Como avaliar esse critério? Determine os seus níveis de impacto.

Quais os níveis de impacto BOM e NEUTRO desse critério?

Comparando-se os critérios par a par, qual dentre os dois possui maior grau de atratividade? (Por exemplo, entre um fornecedor pouco

distante e um muito distante da empresa, qual o melhor?) Responder essa pergunta com base na escala de julgamento semântico a seguir:

\begin{tabular}{|l|l|}
\hline C0 & Indiferente \\
\hline C1 & Diferença de atratividade muito fraca \\
\hline C2 & Diferença de atratividade fraca \\
\hline C3 & Diferença de atratividade moderada \\
\hline C4 & Diferença de atratividade forte \\
\hline C5 & Diferença de atratividade muito forte \\
\hline C6 & Diferença de atratividade extrema \\
\hline
\end{tabular}

Por meio das respostas aos itens 4 e 5 serão construídos os descritores e preenchidas as matrizes de julgamento semântico dos critérios:

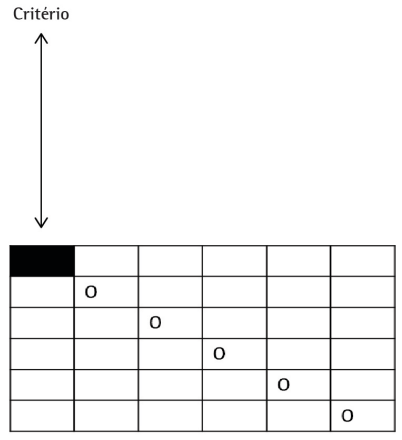


Anexo B. Roteiro de entrevista - Fase 2.

\begin{tabular}{|l|l|}
\hline \multicolumn{2}{|l|}{ Roteiro de entrevista para validação do modelo } \\
\hline Preenchido por: & Cargo: \\
\hline Empresa: & Data: \\
\hline Em sua opinião, o modelo proposto (estrutura arborescente de pontos de vista) permite que a situação problema seja vista da perspectiva \\
apropriada? \\
Essa perspectiva é capaz de auxiliar na condução de soluções apropriadas? \\
Na sua percepção, os critérios foram relacionados corretamente no sentido de representar a situação em questão? \\
Você consegue identificar algum critério ou relação que tenha sido omitido/excluído do modelo proposto? \\
Como você vê a qualidade a aplicabilidade das soluções apresentadas pelo modelo? \\
Como você julga ser possível melhorar o modelo? \\
Quais as vantagens obtidas por meio da utilização do modelo na justificativa de decisões sobre os fornecedores de chapas de aço? \\
E quais são as desvantagens desse modelo decisório?
\end{tabular}

